\title{
WHAT MAKES AUTONOMOUS LEARNING OBJECTIVES AUTONOMOUS: A CASE STUDY FROM HIGHER EDUCATION
}

\author{
Jitka Hlouskova \\ Language Centre, University of Pardubice (Czech Republic)
}

\begin{abstract}
Teachers and other professionals at all levels of education worldwide are aware of the inevitable changes to the existing education systems. Traditional teaching methods are failing to yield effective results when mirrored against the skills graduates need to be able to succeed professionally in the modern globalized world. Responsibility for the preparation of leaders for the world of the future rests strongly with higher education institutions. This paper aims to contribute to the various approaches college and university teachers are adopting to introduce changes to their own teaching in an effort to provide their learners not only with the knowledge in their area of expertise, but also to empower them to become self-directed life-long learners and authentic personalities possessing key competences for the $21^{\text {st }}$ century. The author's approach is based on her belief in the power of autonomous learning as a process the learner goes through from the start line of self-assessment to the finish line of the evaluation of and reflection on learning achievements. The core of this paper lies in the presentation of the results of a case study focused on autonomous learning objectives of students in higher education. It outlines the tools and procedures the learners use when working with an e-portfolio to set themselves their own goals prior to the start of their learning, provides a description of the learner goal categories, and presents a conclusion in terms of what makes learning objectives autonomous. Although the specific context of the case study is language learning, the author aims at a broader perspective to draw more general conclusions about learner autonomy in higher education.
\end{abstract}

Keywords: Higher education, autonomous learning, learning objectives, e-portfolio, case study.

\section{Introduction}

This paper is a contribution to my research into learner autonomy in higher education. My motivation for the investigation results above all from the belief that changes to the existing educational systems are absolutely necessary and inevitable, which has recently been accentuated worldwide. Teachers and professionals in education as well as students, their families and the general public are becoming less and less satisfied with the results of traditional teaching that, in general, has not changed much over the past 200 years. Many institutions are still approaching the teaching and learning processes using methods that are very similar to those used at the times of the industrial revolution. However, the current world is completely different.

As I indicated in the abstract above, the context of the case study presented here is language learning, or English for Specific Purposes specifically. However, the main goal of this particular paper is to present a potential contribution to effective changes within educational processes in the form of an example of how to enhance the concept of autonomous learning objectives in higher education in a broader sense.

\section{Case study}

\subsection{Context}

First of all, let me explain the context of this study. I have worked in higher education for 15 years. A major part of my workload consists of teaching English for Specific, Academic and Scientific Purposes. My research focus has recently moved from English Language Teaching Methodology and Applied Linguistics to the development of learner autonomy. I have been looking for new approaches to teaching to help my students become not only more autonomous learners, but autonomous personalities with an internalised concept of life-long learning and self-development. This is what I believe can 
contribute to success both in their professional careers and personal lives. Having done some training to become a life coach, in the past 2.5 years I have been applying principles of coaching to my teaching and looking into the changes this approach has yielded for my students, the way they learn and how they perceive their own learning, and for myself as a teacher. My goal is to use the results of my investigations to alter the syllabus, methods and requirements of the subjects I teach.

Following this line of research, I started with an introductory study which confirmed that "adopting a coaching approach and applying principles and tools originally used for coaching seems to be desirable in order to help students acquire transferable soft skills valuable for their future professional as well as personal lives." (Hlouskova 2018). Although my initial focus was on teaching and learning English for Specific and Academic Purposes, during the observations and analyses for the purpose of this study I began to see many aspects that are universal to learning in general. Thanks to this I could adopt a more general perspective. It was above all the transformation processes that the students talked about during the interviews that made me think about broader contexts. As far as the theoretical background is concerned, this experience encouraged me to go beyond theories of autonomous language learning (e.g. Holec 1981, Little n.d. or Little, Dam and Legenhausen 2017 or Benson 2011) and read more on coaching, experiential learning and transformative learning (e.g. Whitmore 2009, Kolb 1984 or Mezirow 2002).

\subsection{Methodology}

The specific case for the purpose of this investigation was represented by a group of 17 students enrolled in a post-graduate course of English for Electrical Engineering and IT B2+-C1 at the Faculty of Electrical Engineering and Informatics of the University of Pardubice, Czech Republic, in the academic years 2017 - 2018 and 2018 - 2019. As an introduction to the course, the students were asked to reflect on their previous learning and to do the self-assessment of their current skills. Based on this they were encouraged to set their individual learning objectives for the specific course period (one semester). They were granted access to Mahara, an online e-portfolio tool incorporated in the University LMS Moodle system but were also given the freedom to use another e-portfolio tool according to their own preference (all of them stayed with Mahara although two did not complete the course). In line with the application of coaching principles to the process of learning, the students were instructed to create SMART goals (Specific, Measurable, Agreed/Attainable, Relevant/Realistic, Time phased; cf. Whitmore, 2009). As described in Hlouskova, 2018, "the students were informed that they would evaluate their own goals and the extent to which they managed to achieve them at an interview at the end of the semester as part of their exam."

Upon course completion and after the final interviews, the students' learning objectives were downloaded from their self-assessment and goal setting pages in the Mahara e-portfolio. They had a form of short texts stating the current level of their linguistic competence (with heading such as "what I can do", what works well for me”, etc.) and their objectives for the semester in each language skill, namely listening, reading, spoken interaction, spoken production, writing ( "what I want to learn", "where I want to improve", etc. and "how exactly I am going to do this", which meant formulating the SMART goals). These short texts were then analysed using the mixed approach of qualitative and quantitative content analysis. The process included determining the text units to be coded, developing content categories and analysing the data.

The fundamental research question was:

\section{What makes autonomous learning objectives autonomous?}

\subsection{Results}

Looking for answers to the research question could not been done without referring constantly to the most common definitions of learner autonomy including the one by Holec who described it as "the ability to take charge of one's own learning" (Holec 1981, p. 3), which also means "to take charge of one's learning is to have, and to hold, the responsibility for all the decisions concerning all aspects of this learning" (ibid).

It is important to note that the students found it very difficult to set themselves their individual learning objectives. The main reason they gave during the final interview was that this was a completely new and also unusual task in which they had no or very limited experience as it is usually the teachers that set the objectives. Normally, the students are supposed to achieve them, and there is hardly any discussion about methods, individual learning styles, relevance, etc. Therefore, the course requirements took most of the students by surprise. They were encouraged to think of their specific individual needs and decide what they needed to achieve with respect to the communicative situations they were finding themselves in already or were going to face in the future in their educational, work or personal contexts. 
As students of post-graduate programmes they had had quite a significant history in learning English, they knew their starting line thanks to the self-assessment they had done at the beginning of the course, and now they thought carefully about where they wanted to find themselves at the end of the semester in terms of progress in each of the language skills. Taking all these circumstances into consideration, it is not surprising that the students' goals for each of the language skills were different.

When analysing the content of the students' learning objectives with respect to the nature of learner autonomy, the main attention was paid to what the objectives had in common and how autonomy was reflected in them. As a result, the following categories were developed:

1) Study materials to work with individually in order to achieve the desired objectives.

The majority of the students decided to use materials outside their professional field $(65 \%$ in the case of audio-visual materials used for the improvement of listening comprehension and $76 \%$ in the case of texts used to make progress in reading comprehension; the students also used these materials to develop their spoken production and writing skills ${ }^{1}$ ). When reflecting on their learning during the final interviews, most of them stated that they needed these types of materials to make an actual progress because their English skills related to their field were sufficient. They also emphasized that - to increase their intrinsic motivation - they wanted to go for something different than the materials used in traditional classes.

\section{2) Preferable learning situations and environments.}

The analysis showed that most students preferred situations and environments outside the classroom for individual development of their communicative competence. This was obvious from the material preferences (see above) as well as from the situations and environments they chose to develop their spoken interaction skills: $82 \%$ chose informal education contexts.

\section{3) The target situations in which they knew they would be using their newly acquired} knowledge and skills.

The learning objectives the students set themselves concerned mostly communication in work contexts or personal life $(76 \%)$. As for study reasons, they perceived their competence being in harmony with their needs. This is in line with their choice of study materials and learning contexts.

\subsection{Discussion}

As I stated above, the principle question I had formulated for the purpose of this empirical study was What makes autonomous learning objectives autonomous? The data collection and analysis yielded the following answers: the nature of the approaches that support autonomous learning is reflected in a great variety of objectives that stem from the students' individual needs, learning styles and preferences. This is often difficult to support in traditional teaching in higher education, where the syllabi are usually based on the objectives determined by the instructors. When the students are given more autonomy, they choose study materials and learning contexts according their own preferences. Although they reflect on this particular way of learning as difficult mainly in the initial self-assessment and goal-setting stages, after course completion they conclude that it is more relevant to their needs and more enjoyable, emphasizing the advantages that are in harmony with the essence of autonomous learning as described in the definitions (see above). They appreciate the flexibility, responsibility and increased motivation resulting in better achievements compared to traditional learning. It is also noteworthy that this approach motivated the learners to improve their knowledge and skills beyond the course requirements, which are strictly related to their field of study when set by the course leaders within the traditional concept of teaching in higher education.

\section{Conclusion}

I aimed at more general conclusions about autonomous learning in higher education. However, I need to point out that when collecting and analyzing the data I realized how difficult it was for me to step out of the shoes of a language teacher and researcher into language learning. It would be useful to discuss autonomous learning methods and styles with teachers of other subjects. Hopefully this study can serve as an inspirational example of new approaches to learning and teaching in higher education and encourage more academic discussion.

${ }^{1}$ Detailed results of the analysis are available. They are not presented here as the author wishes to concentrate on a broader perspective of autonomy in higher education, not just (English) language learning and development of the individual language skills. 


\section{References}

Benson, P. (2012). Teaching and Researching Autonomy. Second Edition. Abingdon: Routledge.

Hlouskova, J. (2018). Supporting Learner Autonomy in Higher Education. In Carmo, M. (Ed.) Education and New Developments 2018 (pp. 294 - 297). Lisbon: inScience Press.

Holec, H. (1981). Autonomy in Foreign Language Learning. Oxford: Pergamon.

Kolb, D.A. (1984). Experiential learning: experience as the source of learning and development. Englewood Cliffs, NJ: Prentice.

Little, D. (n.d.). Drawing together the threads of self-assessment, goal-setting and reflection. Retrieved May 30, 2017, from URL http://archive.ecml.at/mtp2/Elp_tt/Results/DM_layout/00_10/ 06/06\%20Supplementary\%20text.pdf.

Little, D., Dam, L. \& Legenhausen, L. (2017). Language learner autonomy: theory, practice and research. Bristol: Multilingual Matters.

Whitmore, J. (2009). Coaching for Performance. GROWing human potential and purpose. The principles and practice of coaching and leadership. London: Nicholas Brealey Publishing.

Mezirow, J. (1997). Transformative Learning: Theory to Practice. New Directions for Adult and Continuing Education, 1997 (74), 5 - 12. Retrieved January 20, 2019, from https://onlinelibrary.wiley.com/journal/15360717. 